\title{
Tra Ponente e Levante
}

\section{Confini, conflitti e contatti nella Trieste letteraria di Vladimir Bartol}

Riassunto: Lo scrittore triestino Vladimir Bartol (Trieste 1903-Ljubljana 1967) è oggi uno degli autori sloveni più tradotti e affermati nel mondo, grazie soprattutto al suo orientalistico e profetico romanzo Alamut (1938). Poco note, tradotte e indagate sono invece le sue opere che hanno per protagonista tematica, motivica e ambientativa la natia Trieste del finis Austriae (Mladost pri Svetem Ivanu - Giovinezza a San Giovanni, 1955-1956) e del governo militare alleato (Tržaške humoreske - Umoresche triestine, 1957). Il contributo si propone di colmare tale lacuna, approfondendo la narrativa bartoliana sui confini e sui conflitti, ma anche sui contatti e sugli scambi che hanno caratterizzato la Trieste del primo Novecento e del secondo dopoguerra, plasmandone tra Ponente e Levante l’odierna identità multiculturale.

\section{Between East and West: Borders, conflicts and contacts in Vladimir Bartol's literary Trieste}

Abstract: Trieste-born Vladimir Bartol (1903-1967) is today one of the most translated and successful Slovenian writers in the world, predominantly thanks to his orientalist and prophetic novel Alamut (1938). Far less known, translated and studied, however, are his other works, mainly set in and inspired by his native town Trieste against the backdrop of finis Austriae (Mladost pri Svetem Ivanu, 1955-1956) and of the allied military government (Tržaške humoreske, 1957). This paper aims to fill this gap, shedding light on Bartoli's narrative on borders and conflicts, but also on the contacts and exchanges that characterized Trieste in the early twentieth century and after World War II, shaping its multicultural identity between East and West. 


\section{Per iniziare}

Quando il pomeriggio del 4 maggio 1946, accettando di buon grado a Divača un passaggio in automobile da alcuni conoscenti, Vladimir Bartol tornava nella natia Trieste dopo ventisette anni di forzato esilio familiare da scrittore ormai maturo, da riconosciuto autore del dramma Lopez (1932), della raccolta di componimenti letterari Al Araf (1935) e del romanzo Alamut (1938), gli parve di scendere lungo tornanti danteschi dall'altipiano ad un approdo profondamente diverso da quello conosciuto alla vigilia del finis Austriae: una città spaccata in due dalla cortina di ferro calata dal Baltico all'Adriatico all'indomani della liberazione dal nazifascismo, un porto dilaniato, conteso tra due blocchi, sistemi, emisferi, un luogo dai mille confini, conflitti e contatti, un territorio libero pericoloso e dal futuro incerto, in cui - scriverà di lì a breve in una novella che ambirà ritrarlo con amara ironia - si capitava

tra borsaneristi e alleati, fascisti e comunisti, neri, italiani e sloveni, tra profughi di ogni sorta, tra ustascia e cetnici, tra esperti colonizzatori anglo-americani, tra partigiani e orfani di guerra, tra ebrei, esuli e annamiti, tra prostitute e democristiane dalle lunghe gonne, tra un'armata di disoccupati - in breve in questa nostra vecchia bellissima Trieste adriatica che gli acuti colonizzatori hanno diviso con audacia senza scrupoli e indugi tra Piazza Unità, dove sono permessi raduni di fascisti, borsaneristi e democristiani, e Piazza Perugino, dove possono, circondati da numerose jeep alleate e auto della polizia, manifestare i lavoratori, le «venderigole» di Ponterosso, i «mandrieri» del circondario e il restante popolo lavoratore; ovvero, in breve, tra Ponente e Levante. ${ }^{1}$

Tornava insomma a casa da straniero, lui, nato nel 1903 nel sobborgo di San Giovanni, emigrato nel 1919 con la famiglia nel Regno dei Serbi, Croati e Sloveni, formatosi come intellettuale e scrittore tra Lubiana, Belgrado e Parigi, e affermatosi appena dopo la morte nel 1967 perlopiù come ininquadrabile autore

1 Vladimir Bartol, Tržaške humoreske, Ljubljana, Cankarjeva založba, 1957, p. 21. Nell'originale: «Zateče se ti s proizvodom svojega vzvišenega duha med črnoborzijance in aleate, med fašiste in komuniste, med črnce, Italijane in Slovence, med begunce vseh odtenkov, med ustaše in četnike, med izkušene angloameriške kolonizatorje, med partizane in vojne sirote, med žide, ezule in Anamite, med prostitutke in dolgokrile demokristjanke, med armado brezposelnih; - skratka v naš stari prelepi Trst ob Jadranu, ki so ga umni kolonizatorji brez skrupulov in pomislekov smelo razplatili na Piazza Unità, kjer je dovoljeno zbirati se fašistom, črnoborzijancem in demokristjanom, in na Piazza Perugino, kjer smejo, obdani od številnih policijskih emergenc in zavezniških jeepov, manifestirati delavci, branjevke s Ponterossa, okoliški mandrijarji in ostalo delovno ljudstvo; ali na kratko, med Zahod in Vzhod» (tutte le traduzioni in italiano sono di Miran Košuta se non diversamente indicato). 
esotico, anazionale, globale, associabile agli occhi dei critici e storiografi letterari non tanto alla sua piccola Heimat emporiale quanto, semmai, al Parnaso centrale sloveno o europeo. Eppure, che la triestinità rappresenti un ineludibile tratto distintivo della sua narrativa e che Bartol rientri a pieno titolo anche nell'Olimpo autoriale della letteratura triestina di lingua slovena, lo comprovano senz'ombra di dubbio almeno due motivazioni specifiche e gemellari: la sua biografia e la sua opera, la sua vita e la sua scrittura, il legame fisico, anagrafico, esterno, e l'empatia spirituale, artistica, intima con Trieste.

\section{La triestinità biografica di Bartol}

Questa trova matematica conferma già da una semplice sottrazione biografica. Bartol visse sessantaquattro anni, perlopiù a Lubiana, per brevi periodi anche a Parigi, Kamnik e Belgrado, ma trascorse più di un terzo della sua esistenza, ben ventisei anni in tutto, nella natia Trieste. Qui, nel rione allora in prevalenza sloveno di San Giovanni, emise il suo primo vagito martedì 24 febbraio 1903, mentre fuori «imperversava la tempesta e le maschere di carnevale strepitavano e urlavano per le strade»; ${ }^{2}$ qui è cresciuto tra le variopinte farfalle del Monte Spacà e i grigi banchi della scuola cirillometodiana sull'Aquedotto fino al forzato esilio cui fu costretto suo padre all'arrivo dell'Italia dopo la prima guerra mondiale; qui prese a suggere il nettare del sapere al ginnasio trilingue di piazza Lipsia proprio negli anni in cui non lontano da lì il pioniere della psicoanalisi italiana Edoardo Weiss testava le teorie freudiane su pazienti e amici, e James Joyce dispensava lezioni d'inglese tanto all'ebreo Ettore Schmitz quanto allo sloveno Boris Furlan; qui «il richiamo del cuore verso la città natale e gli amici di gioventù» lo ricondusse per una visita alla famiglia dello zio insegnante Anton Grmek «a Natale del 1919 e per le vacanze estive del 1923», ${ }^{3}$ una breve sosta nell'autunno del 1926 del viaggio che lo condusse a Parigi per il perfezionamento postuniversitario alla Sorbona; qui ritornò all'indomani della liberazione il 4 maggio 1946 «perché nei venticinque anni di dittatura il fascismo aveva epurato quasi del tutto la vita culturale un tempo fiorente degli sloveni triestini e litoranei», talché grande e urgente si rese a guerra conclusa «la necessità di

2 Vladimir Bartol, Mladost pri Svetem Ivanu, Trst, Založništvo tržaškega tiska, 2001, p. 19. Nell'originale: «Vreme je bilo nevihtno, po ulicah so vriskale in rjovele maškore...».

3 Ivi, p. 7. Nell'originale: «klic srca po rojstnem kraju in po mladostnih prijateljih me je neposredno po mojem izgnanstvu že dvakrat pripeljal k Svetemu Ivanu na obisk k družini mojega strica Antona Grmeka: za božič 1919 in za poletne počitnice 1923». 
attivisti culturali» ${ }^{4}$ tra gli sloveni autoctoni; qui seguitò perciò a rianimare con sacrificio l'attività delle locali associazioni culturali slovene, circoli, gruppi, cori e complessi, soprattutto da presidente della Slovensko-hrvaška prosvetna zveza ('Unione culturale sloveno-croata'), e a collaborare per un decennio da giornalista, critico e recensore di libri, spettacoli teatrali e mostre pittoriche o figurative con il locale quotidiano sloveno «Primorski dnevnik» ('Il quotidiano del Litorale'); qui, in un periodo di stasi solo apparente, non smise di pubblicare letteratura sulla rivista «Razgledi» ('Panorami') e in vari almanacchi locali («Koledar Osvobodilne fronte za tržaško ozemlje», 'Almanacco del Fronte di liberazione per il territorio di Trieste', e «Jadranski koledar», 'Almanacco adriatico'), a concertare inutilmente con la casa editrice Gregorčičeva založba la riedizione dell'ampliata raccolta di prose Al Araf sotto il nuovo titolo di Dve dobi ('Due epoche') e a rinfrancare la propria vena creativa, stendendo umoresche e memorie; e qui, da cittadino formalmente jugoslavo, battagliava di anno in anno con la burocrazia della questura cittadina per il rinnovo del suo permesso di soggiorno, finché nel 1956, acuitasi la tensione al confine tra l'Italia e la Jugoslavia dopo il Memorandum di Londra, le autorità gli negarono l'ospitalità e fu dunque costretto - lui, triestino autoctono - a riparare nuovamente nell'esilio lubianese.

Ma anche nei lunghi decenni passati - come avrebbe titolato Predrag Matvejević «tra asilo ed esilio» ${ }^{5}$ - lontano dalla città natale, Bartol rimase legato a Trieste da un invisibile, carsico, ma indissolubile cordone ombelicale. Lì continuavano infatti a risiedere i suoi parenti, amici, conoscenti, ex compagni di scuola; lì prese avvio nel 1920 col pogrom del Narodni dom ('Casa nazionale') il genocidio fascista ai danni degli sloveni e, per reazione, la clandestina ribellione armata di TIGR e Borba; ${ }^{6}$ lì caddero falciati dal piombo fascista gli eroi di Bazovica/Basovizza e di Opčine/Opicina; da lì seguitava a fargli visita a Lubiana anche dopo il 1956 l'apprensione per il precario destino dei connazionali rimasti, fino a fargli esclamare con i versi di Oton Župančič: «Di voi che ne sarà, o quattro cippi, Gorizia, Maribor, Trieste, Klagenfurt?»; e da lì, infine, l'oboe della

4 Ibid. Nell'originale: «Potreba po prosvetnih delavcih je bila v Trstu, kjer je bil fašizem v petindvajsetih letih svoje strahovlade domala iztrebil nekoč tako cvetoče kulturno življenje tržaških in primorskih Slovencev, velika».

5 Cfr. Predrag Matvejević, Tra asilo ed esilio, Roma, Meltemi editore, 1997.

6 TIGR (acronimo di Trst, Istra, Gorica, Reka) e Borba ('La lotta') erano organizzazioni clandestine antifasciste attive nella Venezia Giulia tra il 1927 e il 1941.

7 Oton Župančič, Zemljevid ('Carta geografica'), in Zbrano delo, a cura di Id., III, Ljubljana, Državna založba Slovenije, 1959 («Zbrana dela slovenskih pesnikov in pisateljev»), p. 37. Nell'originale: «O, kaj bo z vami, vi mejniki štirje, / Celovec, Maribor, Gorica, Trst?...». 
tipografia Graphis intonò nel 1958 con la ristampa del suo capolavoro Alamut, implementata con la prefazione Opombe $k$ drugi izdaji ('Note alla seconda edizione'), quel sonoro «la» editoriale che ne avviò il riscatto critico, la rinascenza artistica e la rivalutazione letteraria nel secondo dopoguerra.

Non sarebbe perciò credibile che un così intimo, saldo e duraturo ormeggio personale al molo della città natale mancasse di incidere il proprio marchio anche sulla creazione letteraria dell'autore. Lapalissiano riverbero di quella biografica, risulta di conseguenza la triestinità letteraria di Bartol, che emerge come il contiguo Timavo dai suoi testi narrativi o drammaturgici: a volte con ipogea intermittenza, appena percettibile sotto la superficie a prima vista esotica, allogena, internazionale delle sue opere, altre volte invece con torrentizio impeto, quando erutta schiumeggiante sulla pagina in tutta la sua evidenza tematica o ambientale.

\section{La triestinità letteraria di Bartol}

Nell'arco evolutivo dell'opera bartoliana entrambe le triestinità appaiono direttamente proporzionali: quanto più tangibile, vissuta in loco era quella biografica, tanto più florida verdeggiava quella letteraria; quanto più lunghe erano le permanenze di Bartol a Trieste, tanto più spesso e profusamente la città diventava scenario della sua prosa. Nei primi lavori infatti, concepiti perlopiù tra Lubiana, Hosta, Kamnik e Parigi, il golfo natale ancora stentava a ispirare la penna dell'autore.

Nell'inedito racconto Don Lorenzo del 1927, ad esempio, ne sostanziano una lontana, appena percettibile eco solo l'ambientazione rinascimentale italiana della vicenda e il fenotipico ritratto del protagonista con le demoniache sembianze dittatoriali di Mussolini o dei detestati compagni triestini di giochi Giorgetto e Menotti, benché lo stesso autore abbia evidenziato in seguito lo stretto legame tra il suo «primo grande autentico testo» e «le esperienze giovanili vissute a San Giovanni e a Trieste». ${ }^{8}$ Anche il dramma Lopez, ambientato nel 1932 tra i baschi in Spagna ma dedito a fustigare chiaramente il marcio, rissoso ambiente letterario della coeva Lubiana, appare immune dall'influenza geoletteraria della città natale.

8 V. Bartol, Mladost pri Svetem Ivanu, cit., p. 269. Nell'originale: «Med takimi osebnejšimi odkritji je bilo zame odkritje podtalnih, meni dotlej neznanih zvez med mojim prvim večjim avtentičnim tekstom Don Lorenzom in med mojimi mladostnimi izkušnjami in doživetji pri Svetem Ivanu in v Trstu». 
Qualche più copiosa, ma forse inconsapevole goccia di triestinità letteraria Bartol l'ha però stillata nella silloge di componimenti letterari Al Araf del 1935. Il cosmopolitismo bohémienne dei suoi «demoni claudicanti» e la creola multiculturalità della sua Parigi non sono infatti del tutto estranei all'internazionalità emporiale del natale porto franco, né l'autore ha mai nascosto di aver tratto spunti fisici, onomastici o caratteriali per i protagonisti di Al Araf proprio da conoscenti, tipi o modelli triestini:

Gran parte degli eroi delle mie novelle e dei miei scritti porta il nome di conoscenti, amici o compagni di scuola della mia giovinezza. Tutti questi nomi mi si sono imposti di per sé, di alcuni ho individuato la remota origine [...] appena mentre scrivevo. Sono nomi quali Forcesin (la signora Forcesin, triestina, è stata un'amica della mamma), Robert Nigris (il dott. Nigris era il nostro medico di famiglia), il dott. Krassowitz (il marito della maestra Ivanka Sabadin era il maestro Ivan Krašovic), [...] Zvonko Karara ne «La cantata del nodo inesplicabile» (Karara si chiamava appunto un mio compagno di classe vissuto per alcuni anni a San Giovanni), Janez Boštjančič ne «Il demone nero» e nel bozzetto «Solo un breve conto» (la stirpe dei Boštjančič ci era nota), France Fonda (un nome conosciuto a San Giovanni), il dott. Grom (è superfluo ricordare Maša Grom) ecc. ecc. ${ }^{9}$

Sebbene gran parte dei lettori, critici e storiografi letterari la ritengano il prototipo dell'esotismo narrativo di Bartol, la sua opera tematicamente più universale, «esportabile» e meno «nazionale», negli ultimi tempi persino il romanzo Alamut, pubblicato nel 1938 a Lubiana dalla casa editrice Modra ptica, risulta vieppiù interpretato in chiave territorialmente triestina, adriatica, quale metafora «della lotta di liberazione degli sloveni litoranei» dall'oppressivo tallone «del potere fascista italiano cui sono stati ingiustamente assegnati dopo la prima guerra mondiale» ovvero, meglio, quale allegorica raffigurazione «degli appartenenti all'organizzazione terroristica TIGR» di cui Bartol sembra fosse «simpatizzante». ${ }^{10}$

9 Ivi, pp. 267-268. Nell'originale: «Večji del junakov v mojih novelah in spisih ima imena znancev, prijateljev ali sošolcev iz moje mladosti. Vsa ta imena so se mi vsilila sama po sebi, za nekatere sem šele med pisanjem [...] ugotovil njihov davni izvor. Tu so imena kakor Forcesin (Tržačanka gospa Forcesinova je bila mamina prijateljica), Robert Nigris (dr. Nigris je bil naš domači zdravnik), dr. Krassowitz (mož učiteljice Ivanke Sabadinove je bil učitelj Ivan Krašovic), [...] Zvonko Karara v »Kantati o zagonetnem vozlu « (Karara se je pisal neki moj sošolec, ki je bival nekaj let pri Svetem Ivanu), Janez Boštjančič v »Črnem vragu« in črtici »Samo kratek račun« (rodbina Boštjančičevih nam je bila znana), France Fonda (znano ime pri Svetem Ivanu), dr. Grom (ni mi treba spominjati na Mašo Gromovo) itd. itd.».

10 Miran Hladnik, Razmerje med Bartolovo kratko in dolgo prozo (Al Araf in Alamut), in Slovenska kratka pripovedna proza, a cura di Irena Novak Popov, Ljubljana, Center za slovenščino kot drugi/tuji jezik pri Oddelku za slovenistiko Filozofske fakultete Univerze v 
Definita «nazionalistica» dal traduttore inglese di Alamut Michael Biggins, ${ }^{11}$ quest'esegesi critica che, nello spirito della distinzione kosoveliana tra nazionalità e nazionalismo, andrebbe invece interpretata piuttosto come «nazionale», trova le sue ineludibili conferme fattuali nella fascinazione bartoliana per Nietzsche e la «Wille zur Macht» etnica di Klement Jug, nell'amicizia dell'autore con l'attivista triestino del TIGR Zorko Jelinčič e nell'inequivocabile annotazione dopo la condanna dell'amico al primo processo del tribunale speciale: «Anche per te, Zorko, verrà il momento della vendetta»;12 ma trova fondamento soprattutto nella confinaria autoctonia adriatica di Bartol che ha instillato anche nella narrazione alamutiana un evidente assillo per $\mathrm{i}$ destini della slovenità, un innegabile attivismo nazionale.

«Già per il solo fatto di essere triestino, di casa dunque ai (minacciati) margini del territorio nazionale sloveno, Bartol non può essere decontestualizzato da quel senso attribuito alla letteratura dall'engagement e dalla volontà di emancipazione nazionale»: ${ }^{13}$ così ha affermato in proposito Miran Hladnik, che ha aderito in sede ermeneutica con ancora maggior convinzione del predecessore Lino Legiša alla lettura locale, triestina del romanzo quando ha affermato con esplicita franchezza nel saggio intitolato Alamut e l'interesse nazionale sloveno:

Caldeggio l'esogena lettura metaforica del romanzo cosmopolita Alamut, una lettura che sappia intravedere nelle sue esotiche vicende una storia slovena. A incanalarci verso una tale lettura sono l'origine litoranea dell'autore, che nel periodo tra le due guerre esigeva per così dire un testo sloveno nazionalmente impegnato, l'appartenenza dell'opera al genere del romanzo storico, che immancabilmente destava nei lettori l'aspettativa di un testo che

Ljubljani, 2006 («Obdobja», 23), p. 137. Nell’originale: «Bartolova kratka proza, posebno Al Araf (1935), ima podobno sporočilo, kot je tisto v njegovem zgodovinskem romanu Alamut (1938). To je ključni argument za t.i. nacionalistično interpretacijo romana, po kateri perzijski branilci utrdbe Alamut iz 11. stoletja ustrezajo pripadnikom slovenske teroristične organizacije TIGR, ki se je borila za osvoboditev primorskih Slovencev izpod fašistične oblasti, ki so ji bili krivično dodeljeni po prvi svetovni vojni. Bartol je bil simpatizer tega narodnoosvobodilnega gibanja». 11 Cfr. Michael Biggins, Against Ideologies: Vladimir Bartol and Alamut, in Vladimir Bartol, Alamut, Seattle, Scala House Press, p. 387.

12 Vladimir Bartol, Zbrano delo, I, Ljubljana, Založba ZRC-ZRC SAZU, 2012 («Zbrana dela slovenskih pesnikov in pisateljev», 252), p. 728. Nell'originale: «Tudi zate, Zorko, pride maščevanje in za vse tvoje prijatelje in naše rojake tam doli».

13 Miran Hladnik, Alamut in slovenski nacionalni interes, Ljubljana, 2002, <http:// lit.ijs.si/alamut2.html>, (consultato il 25.1.2019). Nell'originale: «Bartola si že zato, ker je doma iz Trsta, z (ogroženega) nacionalnega roba, ni mogoče zamišljati zunaj tiste osmislitve, ki jo literaturi podeljujeta slovenski nacionalni angažma in želja po nacionalni emancipaciji». 
difendesse gli interessi nazionali sloveni, e la considerazione dei restanti lavori autoriali che offrono la chiave per la descritta interpretazione del romanzo. ${ }^{14}$

Benché la narrazione di Alamut offra poi in verità pochi appigli concreti a questa lettura metaforica, l'interpretazione del «Genieakkord» bartoliano in chiave nazionale e resistenziale non è legittimata soltanto dall'enciclopedica plurisemia del romanzo ma anche dalle esplicite asserzioni autoriali sulla sua dimensione mitica, metaforica, echianamente aperta e universale, che suonano come una nuova, stavolta diretta conferma della triestinità letteraria di Bartol.

Qualche suo rivolo è confluito nel 1939 anche nel successivo, inedito romanzo Čudež na vasi ('Miracolo al villaggio') che ha sì per proprio poligono ambientativo la tipica periferia slovena di Blatni vrh, ma per miccia concettuale quella stessa psicoanalisi freudiana già assorbita anche dal milieu culturale triestino, dove destava ormai da qualche decennio le attenzioni scientifiche di medici quali Edoardo Weiss e Vittorio Benussi, quelle artistiche di pennelli quali Arturo Nathan e Vito Timmel, o quelle letterarie di penne (ben note anche a Bartol) quali Italo Svevo, Umberto Saba e Giorgio Voghera. Benché il primo approccio dell'autore alla psicoanalisi sia documentato già nel suo periodo universitario lubianese, il suo mentore filosofico Klement Jug certo non gli negò informazioni sugli studi di psicologia sperimentale compiuti a Padova con il triestino Vittorio Benussi (1878-1927), che divenne così, con ogni probabilità, il trait d'union bartoliano con gli ambienti psicoanalitici triestini e, secondo la suggestiva ipotesi prospettata dalla psicoanalista Vlasta Polojaz nel saggio Vladimir Bartol. Un fantasma di Trieste, il perno intellettuale «nella rete di contatti che attraverso Graz» univa «Ljubljana a Padova e che indirettamente collega i due triestini»:

Bartol scopre infatti la psicoanalisi non attraverso Trieste, dove nel contempo sta suscitando tra gli intellettuali un grande fermento [...], ma leggendo Freud a Ljubljana, dove è stato costretto ad andarsene a sedici anni per l'esplodere di un conflitto, che comunque preesisteva alla grande guerra. Infatti, il muro di pregiudizi che divideva nettamente le due etnie, quella italiana e quella slovena, causando una totale e reciproca chiusura culturale [...], si è esacerbato dopo la prima guerra con l'avvento del fascismo, provocando nel

14 Ibid. Nell’originale: «Nagovarjam k metaforičnemu branju navzven svetovljanskega romana Alamut, k takemu branju, ki zna v eksotičnem dogajanju zagledati slovensko zgodbo. K takemu branju usmerjajo avtorjevo primorsko poreklo, ki je v času med prvo in drugo svetovno vojno tako rekoč zahtevalo slovensko nacionalno angažirano besedilo, razločna pripadnost žanru zgodovinskega romana, kar je skorajda brez izjeme pri bralcih vzbujalo pričakovanje, da se bo roman zavzel za slovenske nacionalne interese, in upoštevanje drugih avtorjevih del, v katerih se ponuja ključ za opisano interpretacijo romana». 
contempo delle pesanti eredità sia per quanto riguarda i conflitti intrapsichici che interpsichici. ${ }^{15}$

Tuttavia, molto più che dal romanzo Il miracolo al villaggio o dai lavori fin qui citati, la triestinità letteraria di Bartol risulta sgorgare limpida da due opere scritte per così dire in situ durante la decennale permanenza dell'autore a Trieste tra il 1946 e il 1956, opere che proclamano con orgoglio sin dal titolo la propria appartenenza geoletteraria: la silloge novellistica Tržaške humoreske ('Umoresche triestine') e le memorie Mladost pri Svetem Ivanu ('Giovinezza a San Giovanni'). Nonostante siano state soppesate sulla talvolta ingiusta bilancia assiologica della storiografia letteraria quali opere minori, esse possono essere invece ritenute centrali e dirimenti sotto lo specifico aspetto della triestinità letteraria di Bartol.

\section{Le Umoresche triestine}

Concepite tra l'ottobre 1948 e il gennaio 1949, pubblicate dapprima singolarmente nella rivista triestina «Razgledi» e raccolte poi in volume nel 1957 a Lubiana dalla casa editrice Cankarjeva založba, le Umoresche triestine sostanziano una cronaca satirica sui generis dell'occupazione angloamericana di Trieste e delle traversie ideologiche, politiche, sociali, nazionali e culturali vissute dalla città dopo il ritiro del IX Korpus partigiano nel giugno $1945 \mathrm{e}$ l'istituzione del Territorio libero di Trieste. Sotto il profilo formale, stilistico e di genere, Bartol trasse ispirazione per la loro stesura dal diario personale tenuto ai tempi dell'occupazione napoleonica delle Province illiriche dal suo illustre conterraneo triestino, l'illuminato mecenate e barone Žiga Zois. Secondo il progetto iniziale la raccolta avrebbe dovuto comprendere dieci novelle ma le forti critiche suscitate dalle singole pubblicazioni in rivista e la conseguente attenuazione dell'impeto creativo indussero l'autore a interromperne la scrittura al quarto episodio. La raccolta Umoresche triestine è oggi così composta dai testi Tržaška novela 1948 ('Novella triestina 1948'), Zgodba o gentlemanu, ki je iskal začudenje ('Storia di un gentleman alla ricerca dello stupore'), Mangialupi in umetniki ('Mangialupi e gli artisti') e Mangialupi in ženske ('Mangialupi e le donne').

15 Vlasta Polojaz, Vladimir Bartol- Un fantasma di Trieste, in Rita Corsa, Edoardo Weiss a Trieste con Freud. Alle origini della psicoanalisi italiana. Le vicende di Nathan, Bartol e Veneziani, Roma, Alpes, 2013 («I territori della psiche»), p. 177. 
Il primo pamphlet pone al centro del suo acre mirino satirico il poeta, narratore e drammaturgo stiriano Anton Novačan, viscerale anticomunista e diplomatico della monarchia jugoslava riparato dopo la liberazione a Trieste per sfuggire al potere 'rosso' del maresciallo Tito. Nella finzione novellistica, Novačan è impersonato dal dottor Julius Grad, un tronfio ed egotico retore che entra in contatto a Trieste con il giornalista Jakomin Pertot - lapalissiano alter ego autoriale anche nelle successive prose della silloge - per poter raggiungere, grazie alla mediazione di quest'ultimo, un accordo politico con le nuove autorità e garantirsi così salva la vita nel caso di un'eventuale ritorno in Slovenia. Ma la risposta di Pertot è perentoria:

Il vecchio idillio liberal-clericale è finito. Tu hai dormito per l'intera lotta di liberazione. Tra noi e loro si stende oggi un mare di sangue. Solo in patria puoi lavare le tue colpe. Torna lì e compirai il tuo dovere. ${ }^{16}$

Ovviamente, né il letterario dottor Grad né il vero Novačan seguirono tale consiglio: l'epilogo della novella vede infatti il primo rincasare semplicemente nella sua abitazione triestina per «immergersi in un sonno alquanto agitato», ${ }^{17}$ mentre il secondo seguì la rotta di molti collaborazionisti sloveni emigrando nel 1949 in Argentina e risiedendo poi a Posadas fino alla morte nel 1951.

Un anticomunista non meno acerrimo è ritratto anche nella successiva novella Storia di un gentleman alla ricerca dello stupore, che mette però in berlina un aristocratico lord e uomo d'affari inglese, tale sir Oliver Burke, sodale dell'amministrazione alleata triestina, che impietrisce di stupore per la prima volta nella sua agiata vita borghese vedendo alcuni volontari comunisti armati di pala e piccone riedificare gratuitamente (e perciò con sovversiva minaccia per il sistema capitalista...) i paesi del Carso triestino incendiati e distrutti dai nazifascisti durante la guerra.

Comune protagonista degli ultimi due racconti che compongono la silloge è invece l'italiano Ettore Mangialupi, prototipo letterario di un simpatico, spiritoso e mafioso faccendiere meridionale approdato a Trieste e qui dedito in primo luogo alla borsa nera e alla conquista di cuori femminili. La prosa Mangialupi $e$ gli artisti, intenzionalmente strutturata in forma perlopiù dialogica, contrappone questo antieroe italiano al citato giornalista e amico sloveno Jakomin Pertot,

16 V. Bartol, Tržaške humoreske, cit., p. 41. Nell’originale: «Stare liberalno-klerikalne idile je konec. Ti si narodnoosvobodilno borbo prespal. Med nami in onimi leži danes morje krvi. Če sodeluješ tam, ne moreš pri nas. Opereš se lahko samo v domovini. Vrni se tja in s tem boš storil svojo dolžnost».

17 Ivi, p. 42. Nell'originale: «In slavni mož se je potopil v malce nemirno spanje». 
dipingendo non solo una caterva di differenze caratteriali e concettuali tra i due, ma anche una miriade di più generali antinomie estetiche e filosofiche tra, ad esempio, arte intellettuale e arte emozionale, astrattisti e realisti, concettualisti e sentimentalisti. In Mangialupi e le donne, invece, indagando con divertita ironia il legame del protagonista con la bellissima modella Amoretta Sempreverde, l'autore scandaglia fino agli intimi recessi psicologici il rapporto tra uomo e donna, razionalità ed emozionalità, cervello e cuore, ponendo su un piatto della bilancia etica il vacuo dongiovannismo erotico di Mangialupi e sull'altro il profondo, sincero, fedele ma al tempo stesso anche sofferente e sacrificale sentimento amoroso del proprio raisonneur Pertot.

Il poker novellistico mostra notevoli assonanze con i precedenti racconti bartoliani, in particolare con i componimenti di Al Araf: anche queste prose sono infatti concepite come exempla, testi parenetici tesi a veicolare un messaggio morale o filosofico; anch'esse sono strutturate perlopiù in forma di dialogo tra un protagonista (Mangialupi, Grad) e un antagonista (Pertot); anch'esse danno infine voce alla cosiddetta «tipična bartolovščina», ${ }^{18}$ l'ampio ventaglio di caratteristici temi bartoliani, quali l'amore, la donna, il potere, la psicologia di personaggi eccentrici e dominanti, il dilemma tra apparenza e realtà, ragione e sentimento, fedeltà e tradimento.

Nuove appaiono però le problematiche etniche e politico-ideologiche filigranate nella raccolta, soprattutto il lombrosiano confronto nazionale tra sloveni e italiani o la cankariana antitesi di socialismo e capitalismo, solidarietà e sfruttamento, così come inedita risulta l'intonazione ironica, satirica, a volte persino sarcastica del volume, che non attinge né all'immediato, pantagruelico umorismo alla Rabelais né all'intellettualistica comicità alla Pirandello, ma scaturisce invece tutta dal cortocircuito tra due mondi, tipi, caratteri o idiomi diametralmente opposti: il latino e lo slavo, l'italiano e lo sloveno, il meridionale e il settentrionale, l'estroverso e l'introverso. Nel contrapporre entrambi i poli con ossimorico parossismo l'autore sfoggia anche un'invidiabile padronanza del genere comico adoperando pressoché ogni suo strumento stilistico, formale o strutturale: dalla semplice ironia linguistica (l'insegna Al cieco denomina ad esempio una galleria d'arte; a critici o artisti l'autore affibbia cognomi allusivi quali Furbarelli, Truffaldini ecc.) alla più complessa iperbole o all'impegnativa comicità situazionale della gag e dello sketch. A livello linguistico, inoltre, il confronto tra due mondi, realtà, culture e mentalità diverse è sottolineato anche dall'interpolazione di numerosi dialoghi, frasi o espressioni italiane nell'originale sloveno, le quali, se da un lato evidenziano la lacunosa conoscenza

18 Cfr. Vladimir Bartol, Mladost pri Svetem Ivanu, III, Ljubljana, Sanje, 2006, p. 248. 
autoriale della lingua di Dante a vantaggio del locale vernacolo triestino, dall'altro confermano la ricercata coloritura municipale e litoranea del narrato anche nel registro linguistico.

Nonostante tale sua originalità tematica, strutturale e stilistica la critica non ha accolto l'opera con soverchio entusiasmo. A Bartol ha rinfacciato soprattutto di aver sfruttato la letteratura per polemici fini personali e politici, imputandogli in qualche caso anche punte di vacua trivialità. La raccolta rimane comunque un'interessante testimonianza tanto della poliedricità creativa dello scrittore quanto dei burrascosi anni in cui Trieste si è ritrovata al centro della drammatica contesa ideologica che ha diviso a lungo con un'impenetrabile cortina di ferro l'Europa e il mondo. Sub specie tergestinitatis le Umoresche potrebbero così considerarsi uno tra i libri più paradigmatici della cosiddetta 'letteratura di frontiera'.

\section{Giovinezza a San Giovanni}

Esaurito l'afflato umoristico, Bartol diede poi stura alla sua ritrovata vena creativa attendendo nel 1954-55 a un'opera nuova e più marcatamente autobiografica: le memorie di Giovinezza a San Giovanni. Dopo aver stigmatizzato in forma satirica le ingiustizie del mondo, della società, del tempo, dopo aver affrontato a viso aperto i propri antagonisti ideologici, politici, letterari o etnici, all'autore non rimaneva infatti che sperimentare anche la più difficile e complessa delle esperienze: narrare in prima persona di sé stesso e della propria interiorità, calarsi nell'intimo della propria anima, affrontare il proprio passato 'sommerso' e soppesare senza sconti o indulgenze la propria vita. Il compito gli apparve da subito improbo, insostenibile tanto che i primi tempi dopo il ritorno a Trieste scansò di proposito il natio rione di San Giovanni per non rinfocolare in sé vecchi ricordi, ferite, nostalgie:

Confesso apertamente: ho tergiversato perché avevo paura di incontrare faccia a faccia la mia gioventù sommersa. Avevo paura di imbattermi faccia a faccia in luoghi e persone che pensavo e speravo sarebbero rimasti sepolti per sempre nei cassetti più nascosti, nei recessi più reconditi della mia interiorità. ${ }^{19}$

19 V. Bartol, Mladost pri Svetem Ivanu, Trst, Založništvo tržaškega tiska, 2001, p. 7. Nell'originale: «Odkrito povem: okleval sem, ker me je bilo strah, srečati se iz obraza v obraz z lastno potopljeno mladostjo. Strah me je bilo, srečati se iz obraza v obraz s kraji in z ljudmi, o 
Ma il desiderio di rivivere, riscoprire e raccontare le proprie radici triestine fu più forte della paura. Così, sin dal maggio 1946, Bartol iniziò ad annotare nei propri notes e diari impressioni, ricordi, narrazioni, episodi e aneddoti riguardanti la sua piccola Heimat sangiovannina distillando gli sconvolgimenti e le emozioni allora provate in una plastica e calzante metafora musicale:

Lampi di ricordi e sogni inseguono l'un l'altro con rapidità vertiginosa, come se una mano fuggente scivolasse lungo la tastiera del pianoforte. I suoni si susseguono con tale velocità che non possono più scalzarsi a vicenda dimodoché tutti riecheggiano infine allo stesso tempo in un unico, maestoso corale. ${ }^{20}$

Il rimpatrio mnemonico nel passato ha dato dunque voce al maestoso corale di Giovinezza a San Giovanni, che risuona al contempo come una testimonianza biografica sull'origine, l'infanzia, la giovinezza, l'istruzione e la crescita dell'autore a Trieste fino al trasferimento familiare a Lubiana nel 1919, ma anche come una preziosa confessione riguardo alle croci e delizie della creazione letteraria, soprattutto sulla stesura del romanzo Alamut, cui è dedicato l'intero capitolo conclusivo dell'autobiografia.

Sollecitata dal coevo direttore del «Primorski dnevnik» ('Quotidiano del Litorale') Stanislav Renko, Giovinezza a San Giovanni fu pubblicata a puntate sul locale quotidiano sloveno dal 12 gennaio al 17 ottobre 1955 e dal 12 febbraio al 22 giugno 1956. Benché concepite come un resoconto estremamente ampio e minuzioso della sua vita e della sua opera, le oltre mille pagine di queste memorie furono ritenute da Bartol l'impegno narrativo più lieto e soddisfacente che mai avesse assunto. Dopo gli iniziali tentennamenti emotivi la penna prese a vergare da sé la carta, dando fluido conto in tre libri - intitolati rispettivamente Svet pravljic in čarovnije ('Il mondo delle fiabe e della magia'), Težka je pot do učenosti ('Irta è la via al sapere') e Romantika in platonika sredi vojne ('Romanticismo e platonismo durante la guerra') - della parabola biografica di Bartol, dalla nascita nel 1903 a San Giovanni fino all'esilio familiare oltreconfine e alla successiva genesi del romanzo Alamut. Sabato 11 febbraio 1956 il «Primorski dnevnik» preannunciò ai suoi lettori un ulteriore quarto libro di memorie che avrebbe narrato «il crollo della monarchia austro-ungarica, gli echi della rivoluzione

katerih sem mislil in upal, da bodo ostali za vedno pokopani v zadnjih predalih in najbolj skritih prekatih moje notranjosti».

$20 \mathrm{Ivi}$, p. 12. Nell'originale: «Prebliski spominov in sanj se z blazno naglico podijo drug za drugim, kot da bi begotna roka drsela preko tipk klavirja. $S$ tako naglico se vrstijo zvoki, da ne morejo več drug drugega izbrisati in donijo na koncu vsi hkrati kakor mogočen koral». 
d'ottobre, la dichiarazione di maggio, l'occupazione di Trieste e del Litorale nonché l'emigrazione dell'autore», ${ }^{21}$ ma il volume non fu mai scritto.

Così ai lettori e ai posteri non rimase che la comunque ampia trilogia bartoliana a perpetuare l'autoctona tradizione memorialistica slovena, inaugurata già nell'Ottocento da Josip Godina Verdelski con l'omonima autobiografia Živenje Josipa Godine Verdeljskega ('Vita di Josip Godina Verdeljski', 1879) e implementata nel Novecento soprattutto dalle memorie $I z$ mojega življenja ('Dalla mia vita') che la madre di Bartol, Marica Nadlišek, stilò dal 1927 al 1938 e la rivista triestina «Razgledi» pubblicò poi postume a un decennio di distanza. A differenza di entrambi gli antesignani, Bartol non concepì la propria opera come un mero resoconto autobiografico o artistico, bensì come un più ampio specchio narrativo in cui riflettere anche l'epoca, i personaggi, la vita sociale, culturale, economica, politica, gli usi e i costumi della comunità slovena triestina al tramonto del XIX e agli albori del XX secolo. Anche per questo fu solito attribuire alla sua Giovinezza a San Giovanni un alto valore letterario reputandola tra le sue opere più valide e importanti. Le opinioni della critica e dei lettori furono invece di tutt'altro tono. Il locale foglio cattolico sloveno «Katoliški glas» ('La voce cattolica') ebbe a sindacare ad esempio su «una scrittura estremamente prolissa di cui nessuno intravede la fine. Non si tratta in definitiva né di letteratura né di memorialistica storica; fantasia e realtà si confondono e non sai se Bartol pensi davvero tutto ciò o se è invece soltanto frutto della sua immaginazione».22

Nonostante tali riserve, non si possono però sottacere alcune innegabili qualità dell'opera: essa è infatti prima di tutto un eccezionale documento etnografico e storico sul rione di San Giovanni e su Trieste in generale; testimonia poi, con dovizia di particolari, la vita culturale, economica e politica della città e degli sloveni triestini dall'inizio del XX secolo al termine della prima guerra mondiale; ed è, non ultimo, una preziosa fonte d'informazioni sulla letteratura, la poetica, la mentalità e il pensiero di Vladimir Bartol stesso, soprattutto laddove egli sviscera i motivi profondi della sua arte e i segreti della propria scrittura. Per questo, più che autobiografia, Mladost pri Svetem Ivanu appare un intenso,

21 Autore anonimo, Jutri nadaljevanje spominov "Mladost pri Svetem Ivanu«, «Primorski dnevnik», XII, 11.2.1956, n. 36 (3274), p. 4. Nell'originale: «zlom avstro-ogrske monarhije, odjek oktobrske revolucije, majniško deklaracijo, okupacijo Trsta in Primorske in avtorjevo pot v izgnanstvo».

22 Autore anonimo, Beseda o literaturi pisatelja Vladimira Bartola, «Katoliški glas», VII, 1.9.1955, n. 35, p. 3. Nell'originale: «je to pisanje neskončno razvlečeno in mu nihče ne vidi konca. To končno ni niti literatura niti niso zgodovinski spomini, fantazija in realnost se mešata in ne veš, ali misli Bartol zares, ali se mu le dozdeva». 
imprevedibile romanzo su Bartol, sulla sua narrativa e su Trieste, la prova principe della triestinità letteraria dell'autore ma anche un nodale capitolo della locale storia politica, culturale e artistica.

\title{
6 Per concludere...
}

Che l'empatia biografico-letteraria di Bartol con la città natale abbia profondamente segnato la sua arte, ispirandogli con le memorie Giovinezza a San Giovanni e la silloge Umoresche triestine due opere ritenute ormai capisaldi canonici della letteratura slovena triestina, non è soltanto un'ipotesi critica più o meno plausibile e documentata ma innanzitutto un'intima convinzione personale di Bartol stesso. Più volte nei suoi diari l'autore ha lamentato infatti di sentirsi - al pari del suo concittadino Umberto Saba tra i 'vociani' a Firenze - un pesce letterario fuor d'acqua in mezzo all'imperante realismo sociale della Slovenia centrale, un uomo di mare tra i continentali, uno straniero fatto d'altra pasta e altro spirito. Illuminante in proposito questo passo delle sue memorie:

\begin{abstract}
A Lubiana, piú di qualche contemporaneo mi rinfacciò il fatto di non attenermi con gli altri miei colleghi di penna a una comune corrente, la quale consisterebbe nel descrivere soprattutto personaggi contadini e i loro problemi, le loro tribolazioni. Alcuni giudici inclementi mi hanno attribuito persino una sorta di meschina inclinazione per tematiche 'esotiche', con le quali avrei inteso inquinare il pio e umile lettore sloveno, ghiotto soprattutto di pane d'avena e di crauti, peraltro alquanto salutari. Questa persecuzione fu abbastanza ampia e duratura, ma nessuno si chiese se l'autore di simili tematiche avesse qualche giustificazione per esse e forse persino il dovere, da autore sincero, di scrivere così e non altrimenti, essendo nato e cresciuto, a differenza di gran parte dei suoi illustri colleghi e compagni di sventura letteraria, in un altro ambiente, radicalmente diverso. [...] Chi da bambino guardava ogni giorno le navi provenienti da tutti i continenti del mondo e vedeva quotidianamente nella sua città natale i rappresentanti delle piú disparate nazioni, popoli e razze passeggiare per le vie, chi ha ascoltato linguaggi e melodie ignote, ha immagazzinato nella sua memoria altre impressioni, si è abbandonato nell'infanzia ad altri desideri e fantasie rispetto a chi è nato e cresciuto in mezzo alla quiete patriarcale [...] di qualche villaggio sloveno isolato dal mondo e dal suo più o meno poetico idillio. ${ }^{23}$
\end{abstract}

23 Vladimir Bartol, Pot do učenosti. Mladost pri Svetem Ivanu, II, Ljubljana, Sanje, 2006, pp. 293-294. Nell'originale: «Marsikateri moji sorodniki [sic! Recte: sodobniki, ndt.] so mi v Ljubljani očitali, češ, zakaj se ne držim z ostalimi svojimi pisateljskimi tovariši nekake skupne smeri, ki naj bi bila predvsem v popisovanju kmečkega človeka in njegovih nadlog in težav. Nekateri nedobrohotni sodniki so mi podtikali celo nekakšno podlo veselje do »eksotičnih" snovi, s katerimi da nameravam okužiti skromnega in ponižnega slovenskega bralca, ki naj bi mu teknila 
Bartol, che vedeva attraccare giorno per giorno da bambino le navi provenienti da ogni continente, che incontrava per le vie della sua città gente di ogni etnia, nazione, razza, religione, che prestava continuo ascolto a lingue e melodie ignote e che ha intriso di conseguenza la sua parola d'arte di triestina multiculturalità, cosmopolitismo e 'frontieritudine', può essere ritenuto dunque a ragione autore tanto universale quanto locale, sloveno, cittadino, voce del mondo e della propria casa, scrittore insomma 'glocale'.

Per questo, quando un giorno di luglio del 1956, sottostando con la morte nel cuore all'ennesimo esilio in Jugoslavia impostogli dalle autorità italiane, tornava dopo dieci anni di proficua permanenza litoranea dalla famiglia a Lubiana portando con sé soltanto - come dichiarò al confine - «le valigie verde, piccola, grigia e marrone» traboccanti di effetti personali, «uno zaino» di biancheria intima, «una scatola» con vasetti colmi di bruchi, «un rotolo di coperte lise, due cappotti usati e una vecchia macchina da scrivere», ${ }^{24}$ lasciava in realtà Trieste, $\mathrm{i}$ suoi confini, conflitti e contatti tra Ponente e Levante, un profugo sbagliato, uno straniero in patria e, al contempo, una delle voci più indigene e universali dell'autoctona letteratura slovena.

\footnotetext{
predvsem ovsen kruh in sicer kaj zdravo kislo zelje. Ta gonja je šla še kar precej daleč in na široko, nihče pa se ni pri tem vprašal, če morda nima avtor takih in takih snovi vendarle nekje opravičila zanje in morda celo dolžnosti, da piše kot iskreno izpovedujoč se pisatelj tako in ne drugače, ker se je pač rodil in ker je vzrastel v nekem drugačnem in bistveno različnem okolišu, kakor večina njegovih vrlih kolegov in pisateljskih sotrpinov. [...] Človek, ki je kot otrok sleherni dan lahko gledal ladje, ki so prihajale $\mathrm{z}$ vseh kontinentov sveta, in ki je videl v svojem rojstnem mestu dan za dnem zastopnike najrazličnejših narodov, ljudstev in ras, ki so se sprehajali po njegovih ulicah, poslušal neznane govorice in neznane melodije, je pač nujno nakopičil v svojem spominu drugačne vtise, se je kot otrok nujno predajal drugačnim željam in fantazijam kot nekdo, ki se je rodil in ki je vzrastel sredi patriarhalnega miru [...] od sveta odrezane slovenske vasi in njene bolj ali manj poetične idilike».

24 Vladimir Bartol, Izjava. Documento inedito reperibile nel fondo Bartol presso la Narodna in univerzitetna knjižnica di Lubiana, Ms 2005. Nell'originale: «Izjava. Podpisani Bartol dr. Vladimir se vrača po desetletnem bivanju v Trstu nazaj v FLRJ k svoji družini, ki biva v Ljubljani, Miklošičeva 17. S seboj imam sledeče predmete: 1. Zeleni kovčeg: rokopisi, revije, osebna korespondenca itd. 2. Mali kovčeg: posteljno in osebno perilo, rabljeno 3. Sivi kovčeg: odrezek blaga za letno obleko za ženo, nekaj ženskega perila, toaletne in kuhinjske potrebščine in druge drobnarije, nekaj osebnega rabljenega perila, ena slika, dve osebni rabljeni obleki, nekaj rabljenih kravat in nekaj rabljenega posodja. 4. Rujavi kovčeg (usnjeni): časopisni odrezki, knjige, rokopisi, podloga za plašč, nekaj osebnega rabljenega perila, otroška odeja. 5. Nahrbtnik: osebno rabljeno perilo, copate in razne drobnarije. 6. Škatla: kozarci z gosenicami in nekaj drobnarij. 7. Zavoj: z rabljenimi odejami in tri odrezke blaga za plašče zase in za oba sina. 8. Dva osebna plašča (rabljena) in 9. Rabljen pisalni stroj. Trst, 3.7.1956 (Bartol dr. Vladimir)»
} 